\title{
ANÁLISES DAS DESPESAS SOCIAIS DO GOVERNO FEDERAL NO PERÍODO DE 1988 A 2010
}

\author{
M. C. SILVA*, F. J. V. SOUZA, A. O.ARAUJO e J. D. G. SILVA \\ Universidade Federal do Rio Grande do Norte-Departamento de Ciências Contábeis \\ prof.mauriciocsilva@gmail.com
}

Artigo submetido em outubro/2012 e aceito em dezembro/2014

DOI: $10.15628 /$ holos.2014.1122

\section{RESUMO}

Esta pesquisa tem o objetivo geral de analisar as variações das despesas sociais do Governo Federal, no período de 1988 a 2010. A metodologia envolveu as pesquisas descritiva, bibliográfica, quantitativa $e$ qualitativa para testar as hipóteses que o Governo Federal tem aumentado os gastos com as despesas sociais por ocasião do incremento da arrecadação realização de receitas e se existe preocupação do Governo Federal administrar tais despesas em relação às despesas totais. Os resultados revelaram que a alocação de recursos para as despesas de educação e cultura, habitação e urbanismo e de defesa nacional e segurança pública não foram realizadas com base no incremento das receitas públicas (Aceita $\mathrm{H}_{0}$ ). Para as despesas de saúde e saneamento, trabalho e assistência e previdência social, as variações de 37,90\%, 39,94\% e $73,66 \%$, respectivamente, podem ser explicadas pelas variações (incremento) das receitas totais e existe preocupação do Governo Federal administrar tais despesas em relação às despesas totais $\left(\right.$ Aceita $\left.\mathrm{H}_{1}\right)$.

PALAVRAS-CHAVE: Constituição Federal, Direitos sociais, Despesas sociais, Variações.

\section{ANALYSIS OF THE SOCIAL EXPENDITURE OF THE FEDERAL GOVERNMENT FROM 1988 TO 2010}

\begin{abstract}
This research has as its general objective to analyze the variations of social expenditure of the Federal Government from 1988 to 2010. The methodology involved the descriptive, bibliographical, quantitative and qualitative research in order to test the hypotheses that the Federal Government has increased spending with social expenditure as a result of the increase in tax collection - revenue recognition and if the Federal Government has shown concern in administering such expenditure in relation to the overall expenditure. The results revealed that the allocation of resources for the
\end{abstract}

expenditure of education and culture, housing and urban planning and national defense and public safety did not take place as a result of the increase of public revenues (Accept $\mathrm{HO}$ ). For the expenditure of health and sanitation, labor and social security and assistance, the variations of $37.90 \%, 39.94 \%$ and $73.66 \%$, respectively, can be explained by means of the variations (increase) of the overall revenues and the Federal Government has shown concern when it comes to administering such expenditure in relation to the overall expenditure (Accept H1).

KEYWORDS: Federal Constitution, Social Rights, Social Expenditure, Variations 


\section{INTRODUÇÃO}

A política social em nenhum momento encontra tamanho acolhimento como aconteceu na Constituição de 1988, nos campos da educação (pré-escolar, fundamental, nacional, ambiental etc.), da saúde, da assistência, da previdência social, do trabalho, do lazer, da maternidade, da infância e da segurança, definindo especificamente direitos dos trabalhadores urbanos e rurais, de associação profissional ou sindical, de greve, de participação de trabalhadores e empregadores em colegiados dos órgãos públicos e de atuação de representante dos trabalhadores no entendimento direto com empregadores (VIEIRA, 1997).

A Constituição Federal estabelece que são direitos sociais a educação, a saúde, a alimentação, o trabalho, a moradia, o lazer, a segurança, a previdência social, a proteção à maternidade e à infância e a assistência aos desamparados (BRASIL, 1988). As ações governamentais para cumprirem os direitos sociais que decorrem em desembolso financeiro são registradas como despesas. A Portaria no 42, de 14 de abril de 1999, do Ministério do Planejamento, Orçamento e Gestão (MPOG) esclarece que se deve entender como função, o maior nível de agregação das diversas áreas de despesa que competem ao setor público (BRASIL, 1999).

As principais funções do governo estabelecidas pela referida portaria são: legislativa, judiciária, essencial à justiça, administração, defesa nacional, segurança pública, educação, saúde, trabalho, cultura, habitação, urbanismo, saneamento, assistência social, previdência social etc., totalizando 28 funções. No período de 1988 a 1999, as funções educação e cultura, saúde e saneamento, habitação e urbanismo, defesa nacional e segurança pública e assistência e previdência eram registradas em conjunto.

Nesta perspectiva, a questão de pesquisa é a seguinte: Quais foram as variações das despesas sociais do Governo Federal, no período de 1988 a 2010?

Diante do exposto, a presente investigação tem por objetivo geral analisar as variações das despesas sociais do Governo Federal, no período de 1988 a 2010.

Assumindo a premissa de que o Governo Federal por ocasião de maior arrecadação aloca mais recursos para as despesas sociais e, em consequência, os valores individuais dessas despesas aumentam, a investigação examina:

- 1a hipótese: o Governo Federal tem aumentado os gastos com as despesas sociais por ocasião do incremento da arrecadação - realização de receitas. Análises estatísticas: $H_{0}: \rho=0$ (não existe correlação) e $\mathrm{H}_{1}$ : $\rho \neq 0$ (existe correlação).

- 2a hipótese: o Governo Federal tem aumentado os gastos com as despesas sociais em relação às despesas totais. Análises estatísticas: $H_{0}: \rho=0$ (não existe correlação) e $H_{1}$ : $\rho \neq 0$ (existe correlação).

Considera-se como variável dependente $(X)$ os valores das despesas sociais e como variáveis independentes $(Y)$ os valores das despesas totais e das receitas totais. Foi também utilizado o nível de significância 0,05 (intervalo de confiança de 95\%). 
Nesta pesquisa são consideradas como despesas sociais: educação e cultura; saúde e saneamento; trabalho; habitação e urbanismo, defesa nacional e segurança pública, assistência e previdência social. Na função saúde estão incorporados os valores de alimentação e nutrição; na função assistência e previdência social, os valores de assistência ao idoso, ao portador de deficiência, à criança e ao adolescente e a assistência comunitária e na função habitação e urbanismo as moradias. Na análise foi excluída apenas os valores do lazer que fazem parte da função desporto e lazer, haja vista que os mesmos somente foram registrados no período de 2000 a 2010.

A correlação entre os direitos sociais e as despesas sociais foram realizadas, com base no art. 6ㅇ da Constituição Federal de 1988 e nas despesas (funções) de governo elencadas na Portaria no 42, de 14 de abril de 1999 do MPOG, com a junção de funções (por exemplo: educação e cultura), haja vista que no processo de registros contábeis das despesas públicas, disponibilizados para consulta pública, são incluídos vários gastos na mesma função.

A pesquisa justifica-se pela necessidade de encontrar formas de avaliar os resultados da administração pública. Neste sentido, a utilização de modelagem estatística, segundo Martins (2005), ajuda a testagem e avaliação de hipótese, sem criar leis ou teorias, sendo que o seu valor está em atuar para fornecer subsídios para que o pesquisador utilize as informações relevantes.

Espera-se contribuir com análises que facilitem os cidadãos entenderem as variações das despesas públicas, bem como fomentar mais pesquisas nesta área.A tradução e a interpretação de resultados de gestão pública para os cidadãos são necessárias, haja vista que as pesquisas de Penido et al. (2001) e Miranda et al. (2008) levantaram problemas na compreensão dos elementos integrantes dos demonstrativos públicos e a falta de compreensibilidade das informações produzidas pela contabilidade pública, por parte dos cidadãos comuns quanto de pessoas que trabalham com a mesma.

A pesquisa está estruturada em cinco partes. A primeira (introdução) trata da contextualização do tema. A segunda parte, destaca alguns marcos teóricos para o seu entendimento. As partes seguintes, tratam da metodologia, dos resultados da pesquisa e discussões e as considerações finais, recomendação e conclusão.

\section{RESENHA DA LITERATURA}

\subsection{Recursos Públicos}

O Estado necessita para atender as obrigações constitucionais, segundo Jund (2008), obter as receitas públicas; criar o crédito público (endividamento); planejar e gerir o orçamento público e despender recursos (despesa pública). De acordo com Vieira (2009), o Estado é dotado de funções que vão desde a esfera financeira e estrutural até aspectos sociais e econômicos.

Matias-Pereira (2006) esclarece que as três grandes categorias de atribuições econômicas governamentais propostas por Musgrave são as funções:

i. Alocativa - relaciona-se à alocação de recursos por parte do governo, a fim de oferecer bens públicos (ex. rodovias, segurança), bens semipúblicos ou meritórios (ex. educação e saúde), desenvolvimento (ex. construção de usinas) etc.; 
ii. Distributiva - é a redistribuição de rendas realizada através das transferências, dos impostos e dos subsídios governamentais. Um exemplo é a destinação de parte dos recursos provenientes de tributação ao serviço público de saúde, serviço o qual é mais utilizado por indivíduos de menor renda;

iii. Estabilizadora - é a aplicação das diversas políticas econômicas, a fim de promover o emprego, o desenvolvimento e a estabilidade, diante da incapacidade do mercado em assegurar o atingimento de tais objetivos.

O Estado deve atender as necessidades da coletividade e para tal deve organizar sua administração. A administração pública é o sistema jurídico capaz de impor regras e executar as funções primordiais à coletividade, com o fim de atingir o interesse público.

Há consenso entre os autores no sentido de que a expressão "administração pública" possui mais de um significado. Segundo Carvalho Filho (2009, p.10) isso se deve por duas razões: uma "é a extensa gama de tarefas e atividades que compõem o objetivo do Estado; outra é o próprio número de órgãos e agentes públicos incumbidos de sua execução". Sob o aspecto objetivo, material ou funcional, administração pública "é o conjunto das funções necessárias aos serviços públicos em geral” (MEIRELLES, 2000, p. 59).

Os recursos necessários para a administração pública cumprir seus objetivos são denominados de receitas. Silva (2009) esclarece que denomina-se receita pública o conjunto dos recursos ou rendas que o Estado dispõe entregues através da contribuição da coletividade para fazer face as suas necessidades.

A receita pública é classificada nas categorias econômicas receitas correntes (receita tributária, de contribuições, patrimonial etc.), destinadas a atender as despesas classificáveis em despesas correntes e receitas de capital (operações de crédito, alienação de bens etc.), destinadas a atender as despesas de capital (BRASIL, 1964).

A Lei no. 4.320 de 17 de março de 1964 não define as despesas, apenas as classifica em categorias econômicas (art. 12) em: despesas correntes (despesas de custeio e transferências correntes) e despesas de capital (investimentos, inversões financeiras e transferências de capital) e para atender ao disposto no Parágrafo 1‥ do art. 50 da Lei de Responsabilidade Fiscal (LRF), foram criadas as Despesas Correntes Intra-orçamentárias e as Despesas de Capital Intraorçamentárias.

Com o objetivo de estabelecer um esquema de classificação que disponibilize informações mais amplas sobre as programações de planejamento e orçamento e, também, uniformizar a terminologia a níveis do governo da União, dos Estados, dos Municípios e do Distrito Federal, foi elaborada a discriminação da despesa orçamentária por funções, consubstanciada como Classificação Funcional Programática (KOHAMA, 2009).

Giacomoni (2000, p. 98) esclarece que: “A finalidade principal da classificação funcional é fornecer as bases para a apresentação de dados e estatísticas sobre os gastos públicos nos principais seguimentos em que atuam as organizações do estado". Desse modo, compreende-se que, a classificação funcional veio para melhorar o entendimento dos cidadãos sobre as ações do Governo, pois apresenta informações gerais sobre suas operações, como se fosse um orçamento resumido. 
A classificação por ordem funcional visa conjugar as funções do Governo com os programas a serem desenvolvidos. Esta classificação, parte do entendimento amplo do conceito de função, ou seja, de uma classificação que procure identificar os objetivos da intervenção governamental no desenvolvimento social e econômico da comunidade (KOHAMA, 2009).

Além de definir e elencar as funções de governo (despesas), a Portaria $n=42$, de 14 de abril de 1999, do MPOG, estabelece os seguintes conceitos:

- Subfunção - representa uma partição da função, visando agregar determinado subconjunto de despesa do setor público;

- Programa - é o instrumento de organização da ação governamental que visa à concretização dos objetivos pretendidos, sendo mensurado por indicadores estabelecidos no plano plurianual;

- Projeto - é um instrumento de programação utilizado para alcançar o objetivo de um programa, envolvendo um conjunto de operações, restritas no tempo, das quais resulta um produto que concorre para a expansão ou para o aperfeiçoamento da ação de governo;

- Atividade - é um instrumento de programação para alcançar o objetivo de um programa, envolvendo um conjunto de operações que se realizam de modo contínuo e permanente, das quais resulta um produto necessário à manutenção da ação do governo.

- Operações Especiais - são despesas que não contribuem para a manutenção das ações de governo, das quais não resulta um produto, e não geram contraprestação direta sob a forma de bens e serviços.

A despesa na administração pública é constituída pela obrigação de desembolso financeiro por parte dos cofres do Estado, objetivando financiar as ações do governo, bem como cumprir outras determinações impostas por leis e contratos (BEZERRA FILHO, 2004).

A Resolução do Conselho Federal de Contabilidade (CFC) no 1.121, de 28 de março de 2008, define:

Despesassão decréscimos nos benefícios econômicos durante o período contábil sob a forma de saída de recursos ou redução de ativos ou incremento em passivos, que resultem em decréscimo do patrimônio líquido e que não sejam provenientes de distribuição aos proprietários da entidade.

O Estado para cumprir suas funções (legislativa, judiciária, defesa nacional, segurança pública, saúde, educação, cultura, saneamento etc.) necessita realizar os desembolsos financeiros (pagamentos) decorrentes da contratação de serviços de terceiros, de fornecimento de bens etc. Os desembolsos correspondem às despesas governamentais.

\subsection{Avaliações de Políticas Públicas}

A avaliação das ações governamentais pode ser realizada pelas pesquisas avaliativas de processo e de impacto (resultado). Jannuzzi (2011) esclarece que a pesquisa de avaliação de processo é aquela realizada quando se requer avaliar as atividades de implementação dos programas, a extensão da cobertura do público-alvo atendido, a qualidade dos serviços oferecidos e a pesquisa de avaliação de resultado quando deseja verificar se o programa solucionou o problema social, se o mesmo deve continuar, expandir ou descontinuar. 
A avaliação de impacto, segundo Carvalho (2003), é um instrumental de análise para avaliar a eficiência, a eficácia e a efetividade, ou seja, os impactos das ações promovidas pela política ou programa. A referida autora argumenta que a avaliação inscreve-se no campo das Ciências Sociais Aplicadas e como instrumental de análise, a avaliação vale-se também dos métodos próprios da pesquisa social.

De acordo com Arretche (2009), a literatura de avaliação de políticas públicas costuma distingui-las em termos de sua efetividade, eficácia e eficiência, mas esta distinção é basicamente um recurso analítico destinado a separar aspectos distintos dos objetivos e por consequência, da abordagem e dos métodos e técnicas de avaliação.

Os critérios mais utilizados nas avaliações de políticas públicas são: efetividade (impacto), eficácia, eficiência, sustentabilidade, análise custo-efetividade, satisfação dos beneficiários, insumos (inputs), resultados (outputs), equidade (CAIDEN; CAIDEN, 2001; COSTA; CASTANHAR, 2003).

A efetividade representa o critério de aferição da mudança quantitativa entre o antes e depois da execução de um programa; a eficácia avalia a relação entre os objetivos e instrumentos explícitos de um dado programa e seus resultados efetivos e a eficiência avalia a relação entre o esforço empregado na implementação de uma dada política e os resultados alcançados.

Segundo Costa e Castanhar (2003), a efetividade (ou impacto) indica se o projeto tem efeitos (positivos) no ambiente externo em que interveio, em termos técnicos, econômicos, socioculturais, institucionais e ambientais. O foco desse tipo de estudo, em síntese, é detectar mudanças nas condições de vida de um grupo-alvo ou de uma comunidade, como resultado de um programa e em que medida as mudanças ocorreram na direção desejada.

Para realizar a avaliação de um projeto, Cohen e Franco (2012), chamam a atenção para as técnicas a serem utilizadas e neste sentido esclarecem que pela Teoria da Medição, costumase pensar que a medição utiliza os números apenas em seu sentido quantitativo, mas faz mais isso, os números são símbolos que podem ter dois significados: o quantitativo habitual, que implica que com eles podem ser realizadas operações algébricas, e o qualitativo, que pode significar uma denominação arbitrária ou estabelecer uma ordem.

As análises das variações das despesas sociais do Governo Federal, na perspectiva da pesquisa social, visam esclarecer as situações com a alocação dos recursos nestas despesas em relação às demais e sua correlação com o incremento da arrecadação.

\section{METODOLOGIA}

O delineamento desta investigação adotou os procedimentos metodológicos sugeridos por Beuren et al. (2003). Quanto aos objetivos, optou-se pela pesquisa descritiva; quanto aos procedimentos, a pesquisa bibliográfica e documental e quanto a abordagem do problema, as pesquisas quantitativa e qualitativa.

A pesquisa descritiva, segundo Gil (1999), tem como finalidade descrever as características de determinada população ou fenômeno. Neste sentido são realizadas descrições das despesas de governo. A população (universo) da pesquisa são todas as despesas do governo federal, mas por conveniência, a amostra foi delimitada nas funções: educação e cultura; saúde e 
saneamento; trabalho; habitação e urbanismo, defesa nacional e segurança pública, assistência e previdência social, do período de 1988 a 2010.

Os dados foram extraídos do sítio eletrônico da Secretaria do Tesouro Nacional (STN) www.stn.fazenda.gov.br, já convertidos para a moeda de 2010 pelo IGP-DI (Índice Geral de Preços - Disponibilidade Interna), calculados pela Fundação Getúlio Vargas (FGV). Os valores do Produto Interno Bruto (PIB) foram extraídos do sítio eletrônico do Instituto Brasileiro de Geografia e Estatística (IBGE), expressos a preços correntes.

A plataforma teórica para fundamentar os dados sobre as despesas sociais foi obtida pela pesquisa bibliográfica e documental. Martins e Theóphilo (2009) esclarecem que a pesquisa bibliográfica procura explicar e discutir um assunto, tema ou problema com base em referências publicadas em livros, periódicos, revistas etc. e a pesquisa documental baseia-se em materiais que ainda não receberam tratamento analítico.

A abordagem do problema da pesquisa foi realizada com instrumentos estatísticos e com a descrição dos fatos. Beuren et al. (2003) esclarecem que a pesquisa quantitativa caracteriza por utilizar algum instrumento estatístico, tanto na coleta de dados, quanto no tratamento dos dados e a pesquisa qualitativa por descrever e analisar os fatos.

O tratamento e a análise de dados foram realizados com a utilização dos instrumentos estatísticos: desvio-padrão, média aritmética e o coeficiente de variação (estatística descritiva), e também, o coeficiente de correlação de Pearson, coeficiente de determinação, estatística t ou teste $\mathrm{t}$ (Student), teste $\mathrm{F}$ e o P-valor (inferência estatística). As análises estatísticas foram realizadas com base no que ensinam Levine, Berenson e Stephan (2000), Martins (2002) e Oliveira (2007 e 2010), Bisquerra, Sarriera e Martínez (2004) com a utilização da planilha eletrônica Microsoft Office Excel $2007^{\circledR}$.

\section{RESULTADOS E DISCUSSÕES}

Os resultados da pesquisa constam nas Tabelas 1 a 5 . Foram usadas as seguintes abreviaturas e símbolos: EDU - educação e cultura; SAS - saúde e saneamento; TRA - trabalho; HAB - habitação e urbanismo; DNS - defesa nacional e segurança pública; APS - assistência e previdência social; DS - despesas sociais; DT - despesas totais; RT - receitas totais; DP - desviopadrão; Média - média aritmética; CV - coeficiente de variação; $r$ - coeficiente de correlação de Pearson; $r^{2}$ - coeficiente de determinação; $\mathrm{t}$ - teste $\mathrm{t}$ de Student; $\mathrm{F}$ - teste $\mathrm{F}$.

A Tabela 1 apresenta as análises descritivas das despesas.

Tabela 1 - Análises descritivas das despesas sociais, despesas totais e receitas totais.

\begin{tabular}{l|c|c|c|c}
\hline \multirow{2}{*}{ Estatísticas } & \multicolumn{4}{|c}{ Despesas sociais (1988 a 2010) } \\
\cline { 2 - 5 } & EDU & SAS & TRA & HAB \\
\hline DP & $7.683 .889 .397,85$ & $13.380 .649 .012,97$ & $7.038 .314 .409,83$ & $1.452 .283 .213,50$ \\
\hline Média & $28.446 .872 .632,60$ & $41.594 .146 .979,94$ & $17.479 .724 .394,81$ & $1.645 .254 .754,22$ \\
\hline CV & $27,01 \%$ & $42,17 \%$ & $40,27 \%$ & $88,27 \%$ \\
\hline \multicolumn{4}{|c}{ DS } & DT \\
\hline Estatísticas & DNS & APS & DS \\
\hline DP & $4.111 .866 .911,28$ & $86.558 .942 .275,41$ & $104.651 .884 .116,96$ & $335.747 .270 .152,63$ \\
\hline Média & $26.427 .540 .335,71$ & $208.691 .963 .108,76$ & $324.285 .502 .206,03$ & $1.115 .249 .196 .875,82$ \\
\hline CV & $15,56 \%$ & $41,48 \%$ & $32,27 \%$ & $30,11 \%$ \\
\hline
\end{tabular}




\begin{tabular}{l|c}
\hline Estatísticas & Receitas totais (1988 a 2010) \\
\hline DP & $342.891 .185 .534,00$ \\
\hline Média & $1.177 .211 .456 .977,85$ \\
\hline CV & $29,13 \%$ \\
\hline
\end{tabular}

Fonte: dados da pesquisa.

Observa-se na Tabela 1, que das seis despesas sociais a que mais variou, no período de 1988 a 2010, foi habitação e urbanismo - HAB (CV de 88,27\%). A maior média das despesas sociais foi assistência e previdência social - APS (assistência ao idoso, portador de deficiência etc. e previdência básica, do regime estatutário etc.). Os recursos pagos nesta função variaram de R\$ 122.133.020.833,35 até $\mathrm{R} \$ 295.250 .905 .384,17$ em torno da média ( $\mathrm{R} \$ 208.691 .963 .108,76$ ) análise do desvio-padrão.

Comparando as variações do somatório das despesas sociais (DS) com as despesas totais (DT) e as receitas totais, observa-se que a menor variação (dispersão relativa) ocorreram com as receitas totais (CV de $29,13 \%$ ). Isto significa que as receitas arrecadadas foram mais regulares que as despesas.

O CV de $29,13 \%$ das receitas totais representa média dispersão dos valores em torno da média e média representatividade da média da série e os CV de 32,27\% e 30,11\%, respectivamente, das despesas sociais totais (DT) e das despesas totais do período (DT) significam alta dispersão dos valores em torno da média e baixa representatividade da média da série, conforme ensinamentos de Oliveira (2010).

Os resultados da Tabela 1 comprovam que o Governo Federal teve mais regularidade (menor variação) na aplicação dos recursos em despesas com a defesa nacional e segurança pública - DNS (CV de 15,56\%).

A Tabela 2 apresenta a matriz de correlação das variáveis em análise da pesquisa.

Tabela 2 - Matriz de correlação das despesas sociais, somatório das despesas sociais, despesas totais e receitas totais.

\begin{tabular}{l|r|r|r|r|r|r|r|r|r}
\hline & EDU & \multicolumn{1}{|c|}{ SAS } & \multicolumn{1}{c|}{ TRA } & HAB & DNS & APS & DS & DT & RT \\
\hline EDU & $100,00 \%$ & & & & & & & & \\
\hline SAS & $-7,55 \%$ & $100,00 \%$ & & & & & & & \\
\hline TRA & $7,32 \%$ & $66,89 \%$ & $100,00 \%$ & & & & & & \\
\hline HAB & $-1,43 \%$ & $-13,89 \%$ & $-24,49 \%$ & $100,00 \%$ & & & & & \\
\hline DNS & $71,51 \%$ & $20,10 \%$ & $37,79 \%$ & $9,18 \%$ & $100,00 \%$ & & & & \\
\hline APS & $-5,35 \%$ & $76,74 \%$ & $81,21 \%$ & $1,04 \%$ & $36,02 \%$ & $100,00 \%$ & & & \\
\hline DS & $5,24 \%$ & $80,80 \%$ & $84,13 \%$ & $-0,92 \%$ & $44,21 \%$ & $99,02 \%$ & $100,00 \%$ & & \\
\hline DT & $4,14 \%$ & $55,33 \%$ & $62,51 \%$ & $0,45 \%$ & $33,60 \%$ & $84,79 \%$ & $83,04 \%$ & $100,00 \%$ & \\
\hline RT & $2,37 \%$ & $61,56 \%$ & $63,20 \%$ & $-2,97 \%$ & $29,63 \%$ & $85,82 \%$ & $84,40 \%$ & $97,42 \%$ & $100,00 \%$ \\
\hline
\end{tabular}

Na Tabela 2, observa-se que a associação das variáveis apresenta valores negativos e positivos nas porcentagens e uma magnitude da força de associação que vai de $-24,49 \%$ a $99,02 \%$. Neste sentido somente os valores positivos ou negativos acima de $40 \%$ deverão ser 
analisados, haja vista que se inicia com este percentual a classificação de moderada correlação (BISQUERRA, SARRIERA, MARTíNEZ, 2004, p. 147).

Enquadram-se na análise de correlação (10 passo) em relação às despesas totais (DT), as despesas de saúde e saneamento - SAS (55,33\%); trabalho - TRA (62,51\%), assistência e previdência social - APS $(84,79 \%)$ e em relação às receitas totais (RT), as despesas de saúde e saneamento - SAS (61,56\%); trabalho - TRA $(63,20 \%)$; assistência e previdência social - APS (85,82\%). No caso houve uma coincidência.

Deve-se ressaltar, que nas hipóteses a serem testadas não foram incluídas as correlações entre as despesas sociais (por exemplo, entre as despesas de educação e cultura e defesa nacional e segurança pública).

Os resultados da Tabela 2 evidenciam as correlações a serem testadas.

A Tabela 3 apresenta os coeficientes de determinação da correlação da Tabela 2. Tais coeficientes são analisados para verificar se realmente existe a correlação entre as variáveis.

Tabela 3 - Matriz do coeficiente de determinação das despesas sociais, somatório das despesas sociais, despesas totais e receitas totais.

\begin{tabular}{l|r|r|r|r|r|r|r|r|r}
\hline & EDU & \multicolumn{1}{c|}{ SAS } & \multicolumn{1}{c|}{ TRA } & HAB & DNS & APS & DS & DT & RT \\
\hline EDU & $100,00 \%$ & & & & & & & & \\
\hline SAS & $0,57 \%$ & $100,00 \%$ & & & & & & & \\
\hline TRA & $0,54 \%$ & $44,74 \%$ & $100,00 \%$ & & & & & & \\
\hline HAB & $0,02 \%$ & $1,93 \%$ & $6,00 \%$ & $100,00 \%$ & & & & & \\
\hline DNS & $51,14 \%$ & $4,04 \%$ & $14,28 \%$ & $0,84 \%$ & $100,00 \%$ & & & & \\
\hline DS & $0,29 \%$ & $58,89 \%$ & $65,96 \%$ & $0,01 \%$ & $12,97 \%$ & $100,00 \%$ & & & \\
\hline DT & $0,27 \%$ & $65,28 \%$ & $70,78 \%$ & $0,01 \%$ & $19,54 \%$ & $98,05 \%$ & $100,00 \%$ & & \\
\hline RT & $0,17 \%$ & $30,61 \%$ & $39,07 \%$ & $0,00 \%$ & $11,29 \%$ & $71,90 \%$ & $68,96 \%$ & $100,00 \%$ & \\
\hline
\end{tabular}

Fonte: dados da pesquisa.

$\mathrm{Na}$ análise de correlação (Tabela 3), os coeficientes de determinação (2o passo) indicam que as variações nas despesas de saúde e saneamento - SAS, trabalho - TRA e assistência e previdência social (APS) poderão ser explicados, tanto pelas variações nas despesas totais (DT), quanto pelas variações nas receitas totais (RT).

Verifica-se que apenas $37,90 \%$ das despesas de saúde e saneamento podem ser explicadas pelas variações nas receitas (arrecadação) e 62,10\% (o restante, ou seja, $1-r^{2}$ ) não é explicada pela variação (atribui tal variação a outros fatores não contemplados no estudo).

A maior explicação das variações $(73,66 \%)$ ocorreu nas despesas de assistência e previdência social, sendo que $26,34 \%$ não podem ser explicados.

Quanto aos resultados em relação às despesas totais, 71,90\% das variações das despesas de assistência e previdência social podem ser explicados pelas variações das despesas totais do governo e $28,10 \%$ não podem ser explicados. 
Os valores do coeficiente de correlação de Pearson (Tabela 2) e dos coeficientes de determinação (Tabela 3 ) indicam apenas os dois passos iniciais para se testar as duas hipóteses levantadas.

As Tabelas 4 e 5 apresentam os resultados finais para que se possa concluir pela existência ou não da correlação.

Tabela 4 - Análises dos resultados da 1a hipótese (despesas sociais versus receitas totais).

\begin{tabular}{l|l|l|l|l|l}
\hline \multicolumn{2}{c|}{ EDU X RT } & \multicolumn{2}{c}{ SAS X RT } & \multicolumn{2}{c}{ TRA X RT } \\
\hline $\mathrm{t}=0,1085$ & P-valor $=0,9145$ & $\mathrm{t}=3,5801$ & $\mathrm{P}$-valor $=0,0017$ & $\mathrm{t}=3,7372$ & $\mathrm{P}$-valor $=0,0012$ \\
\hline $\mathrm{F}=0,0117$ & P-valor $=0,9145$ & $\mathrm{~F}=12,8176$ & $\mathrm{P}$-valor $=0,0017$ & $\mathrm{~F}=13,9668$ & $\mathrm{P}$-valor $=0,0012$ \\
\hline$r=2,37 \%$ & $r^{2}=0,06 \%$ & $r=61,56 \%$ & $r^{2}=37,90 \%$ & $r=63,20 \%$ & $r^{2}=39,94 \%$ \\
\hline \multicolumn{3}{c|}{ DNS X RT } & \multicolumn{2}{c}{ APS X RT } \\
\hline $\mathrm{t}=-0,1359$ & P-valor $=0,8931$ & $\mathrm{t}=1,4214$ & P-valor $=0,1698$ & $\mathrm{t}=7,6624$ & P-valor $=0,0000$ \\
\hline $\mathrm{F}=0,0184$ & P-valor $=0,8931$ & $\mathrm{~F}=2,0204$ & $\mathrm{P}$-valor $=0,1698$ & $\mathrm{~F}=58,7134$ & P-valor $=0,0000$ \\
\hline$r=-2,97 \%$ & $r^{2}=0,09 \%$ & $r=29,63 \%$ & $r^{2}=8,78 \%$ & $r=85,82 \%$ & $r^{2}=73,66 \%$ \\
\hline
\end{tabular}

Os coeficientes de correlação de Pearson $(r)$ e de determinação $\left(r^{2}\right)$ das despesas de educação e cultura - EDU, habitação e urbanismo - HAB e de defesa nacional e segurança pública (DNS) foram desconsiderados nas análises realizadas das Tabelas 2 e 3. Os resultados do P-valor do teste $\mathrm{t}$ e do teste $\mathrm{F}$ como foram superiores a 0,05 confirmam a não existência de correlação $\mathrm{e}$ esclarecem o motivo de suas exclusões do processo de análise. Assim, conclui-se que em relação ao incremento da arrecadação, o Governo não alocou recursos para estas despesas (Aceita $\mathrm{H}_{0}$ ).

Como os resultados do P-valor do teste $t$ e do teste $F$ das despesas de saúde e saneamento - SAS, trabalho - TRA e assistência e previdência social (APS) apresentaram valores inferiores a 0,05, pode-se concluir pela existência da correlação com um intervalo de confiança de $95 \%$. Desse modo, o Governo alocou recursos nestas despesas em relação ao incremento de receitas (aceita $\mathrm{H}_{1}$ ). As variações de 37,90\%, 39,94\% e 73,66\%, respectivamente para as despesas de saúde e saneamento (SAS), trabalho (TRA) e assistência e previdência social (APS) podem ser explicadas pelas variações nas receitas totais e $62,10 \%, 60,06 \%$ e $26,34 \%$ não são explicadas no estudo $\left(1-r^{2}\right)$.

Tabela 5 - Análises dos resultados da 2 a hipótese (despesas sociais versus despesas totais).

\begin{tabular}{l|l|l|l|l|l}
\hline \multicolumn{2}{c|}{ EDU X DT } & \multicolumn{2}{c}{ SAS X DT } & \multicolumn{2}{c}{ TRA X DT } \\
\hline $\mathrm{t}=0,1897$ & $\mathrm{P}$-valor $=0,8513$ & $\mathrm{t}=3,0439$ & $\mathrm{P}$-valor $=0,0061$ & $\mathrm{t}=3,6697$ & $\mathrm{P}$-valor $=0,0014$ \\
\hline $\mathrm{F}=0,0360$ & P-valor $=0,8513$ & $\mathrm{~F}=9,2654$ & $\mathrm{P}$-valor $=0,0061$ & $\mathrm{~F}=13,4670$ & $\mathrm{P}$-valor $=0,0014$ \\
\hline$r=4,14 \%$ & $r^{2}=0,17 \%$ & $r=55,33 \%$ & $r^{2}=30,61 \%$ & $r=62,51 \%$ & $r^{2}=39,07 \%$ \\
\hline
\end{tabular}

\begin{tabular}{l|l|l|l|l|l}
\hline \multicolumn{2}{c|}{ HAB X DT } & \multicolumn{2}{c}{ DNS X DT } & \multicolumn{2}{c}{ APS X DT } \\
\hline $\mathrm{t}=0,0208$ & $\mathrm{P}$-valor $=0,9835$ & $\mathrm{t}=1,6349$ & $\mathrm{P}$-valor $=0,1169$ & $\mathrm{t}=7,3300$ & -valor $=0,0000$ \\
\hline $\mathrm{F}=0,0004$ & $\mathrm{P}$-valor $=0,9835$ & $\mathrm{~F}=2,6730$ & $\mathrm{P}$-valor $=0,1169$ & $\mathrm{~F}=53,7290$ & $\mathrm{P}$-valor $=0,0000$ \\
\hline$r=0,45 \%$ & $r^{2}=0,00 \%$ & $r=33,60 \%$ & $r^{2}=11,29 \%$ & $r=84,79 \%$ & $r^{2}=71,90 \%$ \\
\hline
\end{tabular}

Os resultados da Tabela 5 também ratificam a não existência de correlação entre as despesas de educação e cultura, habitação e urbanismo e de defesa nacional e segurança pública em relação a administração das despesas totais do Governo Federal (os P-valor do teste t e do teste $F$ são superiores a 0,05 , neste caso aceita $\mathrm{H}_{0}$ ). 
As despesas de saúde e saneamento, trabalho e assistência e previdência social apresentaram valores inferiores a 0,05 no P-valor para os testes t e F. Desse modo, ratifica-se a existência da correlação (aceita-se $\mathrm{H}_{1}$ ). O Governo Federal tem aumentado os gastos com as despesas sociais em relação às despesas totais. As variações das referidas despesas podem ser explicadas pelas variações nas despesas totais. Isto evidencia preocupação em administrar tais recursos em relação às despesas totais. As variações de 30,61\%, 39,07\% e 71,90\%, respectivamente, para as despesas de saúde e saneamento, trabalho e assistência e previdência social podem ser explicadas pelas variações nas despesas totais e 69,39\%, 60,93\% e $28,10 \%$ não são explicadas no estudo $\left(1-r^{2}\right)$.

\section{CONSIDERAÇÕES FINAIS}

No período de 1988 a 2010, das seis despesas sociais analisadas (educação e cultura; saúde e saneamento; trabalho; habitação e urbanismo; defesa nacional e segurança pública; assistência e previdência social), habitação e urbanismo foi a que mais variou. A maior média das despesas sociais foi com a função assistência e previdência social.

As variações das despesas sociais totais em relação com as variações das receitas totais (arrecadação), foi verificado menor dispersão relativa das receitas totais, o que significa maior regularidade das mesmas e em consequência a alocação de recursos foi mais instável para as referidas despesas.

As variações das despesas com assistência e previdência social tiveram um maior relacionamento (correlação) com a variação das receitas totais. Isto significa que houve preocupação com a alocação de recursos nestas despesas em face da arrecadação.

Estatisticamente não houve correlação entre a arrecadação e as aplicações de recursos nas funções educação e cultura, habitação e urbanismo e defesa nacional e segurança pública.

$\mathrm{Na}$ análise de correlação entre as despesas sociais totais e as despesas totais (todas as despesas executadas), somente as despesas de saúde e saneamento, trabalho e assistência social tiveram resultados estatísticos considerados robustos.

Finalizando o estudo e respondendo o problema com base nas hipóteses levantadas, conclui-se que a alocação de recursos para as despesas de educação e cultura, habitação e urbanismo e de defesa nacional e segurança pública não foram realizadas com base no incremento das receitas públicas (Aceita $\mathrm{H}_{0}$ ). Para as despesas de saúde e saneamento, trabalho e assistência e previdência social as variações de 37,90\%, 39,94\% e 73,66\%, respectivamente, podem ser explicadas pelas variações (incremento) das receitas totais e existe preocupação do Governo Federal administrar tais despesas em relação às despesas totais (Aceita $\mathrm{H}_{1}$ ).

\section{REFERÊNCIAS BIBLIOGRÁFICAS}

1. ARRETCHE, M. T. S. Tendências nos Estudos sobre Avaliação, in: RICO, E. M. (org.). Avaliação de políticas sociais: uma questão em debate. 3. ed. São Paulo, Cortez, 2009.

2. BEUREN, I. M. (Org.). Como elaborar trabalhos monográficos em contabilidade: teoria e prática. São Paulo: Atlas, 2003. 
3. BEZERRA FILHO, J. E. Contabilidade pública: teoria, técnica de elaboração de balanços e 300 questões. Niterói: Impetus, 2004.

4. BISQUERRA, R; SARRIERA, J. C.; MARTÍNEZ, F. Introdução à estatística: enfoque informático com o pacote estatístico SPSS. Porto Alegre: Artmed, 2004.

5. CAIDEN; G. E.; CAIDEN, N. J. Enfoques y lineamientos para el seguimiento, la medición y la evaluación del desempeño en programas del sector público. Revista do Serviço Público. Ano 52, Número 1, Jan-Mar 2001.

6. CARVALHO, S. N. Avaliação de programas sociais: balanço das experiências e contribuição para o debate. São Paulo em Perspectiva, 17(3-4): 185-197, 2003.

7. COHEN, E.; FRANCO, R. Avaliação de projetos sociais. 10. ed. Petrópolis: Vozes, 2012.

8. COSTA, F. L.; CASTANHAR, J. C. Avaliação de programas públicos: desafios conceituais e metodológicos. RAP, Rio de Janeiro 37 (5): 969-92, Set./Out. 2003.

9. BRASIL. Constituição da República Federativa do Brasil de 1988. Diário Oficial [da] República Federativa do Brasil, no 191-A, de 05 out. 1988.

10. BRASIL. Lei Complementar $n^{\circ} 101$, de 04 de maio de 2000. Estabelece normas de finanças públicas voltadas para a responsabilidade na gestão fiscal e dá outras providências. Diário Oficial [da] República Federativa do Brasil, Brasília, 05 de maio de 2000.

11. BRASIL. Lei no 4.320, de 17 de março de 1964. Estatui normas gerais de direito financeiro para elaboração e controle dos orçamentos e balanços da União, Estados, Municípios e do Distrito Federal. Diário Oficial [da] República Federativa do Brasil, Brasília, DF, 23 de março de 1964.

12. BRASIL. Ministério do Planejamento, Orçamento e Gestão (MPOG). Portaria no 42, de 14 de abril de 1999. Atualiza a discriminação da despesa por funções de que tratam o inciso I do §

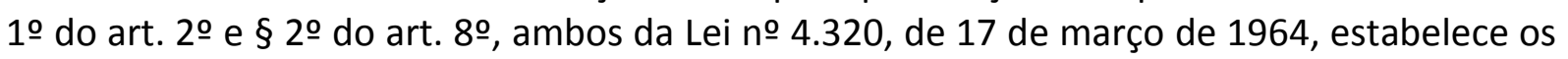
conceitos de função, subfunção, programa, projeto, atividade, operações especiais, e dá outras providências. Diário Oficial [da] República Federativa do Brasil, Brasília, DF, 15 de abril de 1999.

13. BRASIL. Ministério da Fazenda. Secretaria do Tesouro Nacional (STN). Estatística. Disponível em: < http://www.stn.fazenda.gov.br/estatistica/est_contabil.asp>. Acesso em 01 nov. 2011.

14. CARVALHO FILHO, J. S. Manual de direito administrativo. 22. ed. Rio de Janeiro: Lumen Juris, 2009.

15. CONSELHO FEDERAL DE CONTABILIDADE (CFC). Resolução no 1.121, de 28 de março de 2008. Aprova a NBC T 1 - Estrutura conceitual para a elaboração e apresentação das demonstrações contábeis.

16. GIACOMONI, J. Orçamento público. 9. Ed. São Paulo: Atlas, 2000.

17. GIL, A. C. Métodos e técnicas de pesquisa social. São Paulo: Atlas, 1999.

18. Instituto Brasileiro de Geografia e Estatística (IBGE). Contas nacionais trimestrais. Disponível em: <www.ibge.gov.br>. Acesso em: 20 dez. 2011.

19. JUND, S. Administração, orçamento e contabilidade pública: teoria e 850 questões. 3. ed. Rio de Janeiro: Elsevier, 2008. 
20. JANNUZZI, P. M. Avaliação de programas sociais no Brasil: repensando práticas e metodologias das pesquisas avaliativas. Planejamento e Políticas Públicas - PPP, n. 36, jan./jul. 2011.

21. KOHAMA, H. Contabilidade pública: teoria e prática. 10. ed. São Paulo: Atlas, 2009.

22. LEVINE, D. M.;BERENSON, M. L.; STEPHAN, D. Estatística: teoria e aplicações,usando Microsoft Excel em Português. Rio de Janeiro: L T C, 2000.

23. MARTINS, G. A. Estatística geral e aplicada. 2. ed. São Paulo: Atlas, 2002.

24. MARTINS, G. A. Falando sobre teorias e modelos nas ciências contábeis. BBR - Brazilian Business Review, Vol. 2, No. 2, Vitória-ES, Brasil - Jul / Dez 2005, pp. 131-144.

25. MIRANDA, L. C. et al. Uma análise sobre a compreensibilidade das informações contábeis governamentais comunicadas pelo Balanço Orçamentário. BBR - Brazilian Business Review, Vol. 5, N.3 Vitória-ES, Set - Dez 2008, p. 209-228 - ISSN 1807-734X.

26. MARTINS, G. A; THEÓPHILO, C. R. Metodologia da investigação científica para ciências sociais aplicadas. 2. ed. São Paulo: Atlas, 2009.

27. MATIAS-PEREIRA, J. Finanças públicas: a política orçamentária do Brasil. 3. ed. São Paulo: Atlas, 2006.

28. MEIRELLES, H. L. Direito administrativo brasileiro. 25. ed. São Paulo: Malheiros, 2000.

29. OLIVEIRA, F. E. M. SPSS básico para análise de dados. Rio de Janeiro: Ciência Moderna, 2007.

30. OLIVEIRA, J. U. C. Estatística: uma nova abordagem. Rio de Janeiro: Ciência Moderna, 2010.

31. PENIDO, A. M. S. et al. A compreensão dos cidadãos acerca dos demonstrativos públicos: uma análise em três municípios mineiros. In: XXXV ENCONTRO DA ANPAD, 2011, Rio de Janeiro. Encontro da Associação Nacional de Pós-graduação e Pesquisa em Administração. Anais ... Rio de Janeiro: ANPAD, 2001. v. XXXV. p. 1-13.

32. SILVA, L. M. Contabilidade governamental: um enfoque administrativo da nova contabilidade pública. 8. ed. São Paulo: Atlas, 2009.

33. VIEIRA, A. S. Utilização de informações contábeis governamentais para análise da eficiência de políticas sociais dos municípios alagoanos. 2009. 190 f. Dissertação (Mestrado) Programa de Pós-graduação em Ciências Contábeis, Universidade Federal de Pernambuco, Recife, 2009.

34. VIEIRA, E. A. Políticas sociais e direitos sociais no Brasil. Comunicação \& Educação, São Paulo. (9): 13 a 17, maio/ago. 1997. 